HEALTH ECONOMICS

Health Econ. 18: S147-S156 (2009)

Published online in Wiley InterScience (www.interscience.wiley.com). DOI: 10.1002/hec.1507

\title{
AN ANALYSIS OF LIFE-COURSE SMOKING BEHAVIOR IN CHINA
}

\author{
DON KENKEL ${ }^{\mathrm{a}, \mathrm{b}}$, DEAN R. LILLARD ${ }^{\mathrm{a}, \mathrm{c}, *}$ and FENG LIU ${ }^{\mathrm{d}}$ \\ ${ }^{a}$ Cornell University, Policy Analysis and Management, $N Y$, USA \\ ${ }^{\mathrm{b}}$ National Bureau of Economic Research, USA \\ ${ }^{\mathrm{c}}$ Deutsches Institüt für Wirtschaftsforschung, Berlin \\ ${ }^{\mathrm{d}}$ Shanghai University of Finance and Economics, Shanghai, China
}

\begin{abstract}
SUMMARY
With a total population of more than 1.3 billion people where more than $31 \%$ of adults smoke, China has become the world's largest producer and consumer of cigarettes. We adopt a life-course perspective to study the economics of smoking behavior in China. We use data from the China Health and Nutrition Survey (CHNS) to follow individuals over their whole lives and to analyze their decisions to both start and stop smoking. We extend the small but growing body of economic research on smoking in China. Our life-course approach emphasizes that current smoking participation reflects a decision to start and a series of past decisions to not quit. We explore how the determinants of smoking initiation differ from the determinants of smoking cessation. We find results, consistent with some previous empirical evidence, that Chinese smoking is not strongly related to the price of cigarettes. Based on our results, we offer some speculative hypotheses that, we hope, might guide future research on the economics of smoking in China. It seems especially useful to compare the broad patterns we document with the experiences of other countries. Copyright (C) 2009 John Wiley \& Sons, Ltd.
\end{abstract}

KEY WORDS: smoking initiation and cessation; tobacco control; life-course

\section{INTRODUCTION}

With a total population of more than 1.3 billion people where more than $31 \%$ of adults smoke, China has become the world's largest producer and consumer of cigarettes (WHO, 2008). As there is a absence of large changes in the propensity to quit, it is estimated that over half of the 300 million current smokers in China will eventually die of smoking-related diseases (Lam et al., 1997; Liu et al., 1998).

We adopt a life-course perspective to study the economics of smoking behavior in China. We use data from the China Health and Nutrition Survey (CHNS) to follow individuals over their whole lives and to separately analyze their decisions to start and stop smoking. We extend the small but growing body of economic research on smoking in China in several ways. A number of studies focus on the price-responsiveness of cigarette demand in China (Mao et al., 1997; Mao and Jiang, 1997; Hu and Mao, 2002; Bishop et al., 2004; Lance et al., 2004). We use retrospective data from the 2000 wave of the CHNS to examine smoking over a longer time frame than previous studies, from 1952 to 2000. Our lifecourse approach emphasizes that current smoking participation reflects a decision to start and a series of past decisions to not quit (DeCicca et al., 2008). We explore how the determinants of smoking initiation differ from the determinants of smoking cessation.

*Correspondence to: Department of Policy Analysis and Management, 296 MVR Hall, Cornell University, Ithaca, NY 14853-4401, USA. E-mail: DRL3@ cornell.edu 
In Section 2 we briefly summarize the history of Chinese tobacco control policies. In Section 3 we describe our data from the CHNS, and present life-course smoking patterns that we derive using those data. In Section 4, we describe our econometric models of smoking participation, initiation and cessation. Section 5 describes the results. In Section 6 we discuss the results and draw policy implications.

\section{TOBACCO CONTROL POLICY IN CHINA}

While China's tobacco control policies are broadly similar to policies elsewhere, they evolved differently. Figure 1 shows the average retail price of cigarettes from 1952 to 1992 and the tobacco price index for 1993-2003 (China Statistical Yearbook, 1985-2003). Before 1978 there was less year-to-year variation in cigarette price because the central government set all (official) prices. After the government introduced limited market reforms in 1978, the inflation-adjusted cigarette price rose dramatically.

Like other countries, China controls tobacco use with taxes, smoking bans, advertising restrictions and warning label requirements. Combined taxes comprise about $38 \%$ of the retail price of cigarettes (Hu and Mao, 2002). China first restricted who could smoke in 1981 when they made it illegal for middle school students to smoke and they first prohibited tobacco marketers from advertising on radio, television and in newspapers in 1987. In subsequent years they broadened the prohibitions on youth smoking and the advertising ban. Like other countries, China requires packaging of cigarettes and cigars to list tar levels and to carry health warnings. Since 1994, about 100 cities have issued local laws or regulations that ban smoking in public places where people gather.

\section{DATA ON LIFE-COURSE SMOKING}

We use data from the CHNS - a panel survey which began in 1991 with a sample of about 4400 households with a total of 16000 individuals. ${ }^{1}$ Table I provides descriptive statistics for the pooled CHNS sample.

As Table I documents, Chinese men are much more likely to smoke than Chinese women, they smoke more, and they started earlier. Smoking rates are very similar across wealth quartiles and rural/ urban status. However, smoking rates vary substantially across schooling levels.

Using retrospective data from the 2000 wave, we code and plot life-course smoking prevalence rates of men and women aged 21-60 in 2000. We use survey questions on current and past smoking behavior to code a person's smoking status in each year of life from 1952 to 2000 . We can do this because the survey asks the age smokers began to smoke and it asks ex-smokers how long ago they quit. In US data Kenkel et al. (2003a) compare smoking status with retrospective and contemporaneous reports. They document that this approach provides reasonably reliable measures of smoking behavior as far as 20 years in the past. Further, Lillard et al. (2009) use US data with retrospectively reported data on behavior as long as 80 years in the past to develop a method to reduce reporting bias in retrospective data. We explore their method in an alternative specification.

Figure 2 shows that mens' smoking rates across the life course do not vary much by birth cohort. Chinese men of different cohorts begin to smoke around the age of 14 and most who ever will smoke have started smoking by age 25 - a pattern strikingly similar to the pattern found among US, British and Russian men (Kenkel et al., 2003b). However, unlike US and British men but similar to Russian men, on average, between 60 and $70 \%$ of Chinese men continue to smoke into middle age.

\footnotetext{
${ }^{1}$ Surveys were administered in 1989, 1991, 1993, 1997, 2000, 2004 and 2006. No smoking questions were asked in 1989 and community level cigarette prices are not yet available for 2006. http://www.cpc.unc.edu/projects/china.
} 


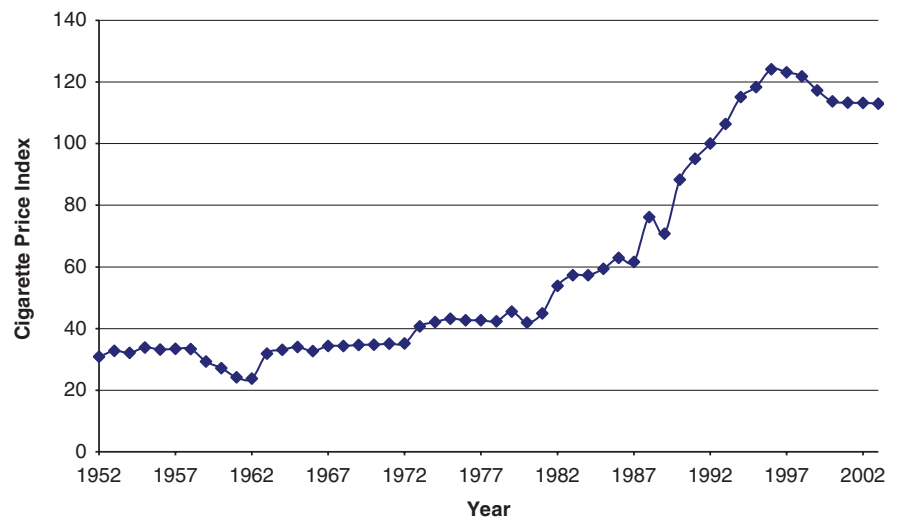

Figure 1. Cigarette Price Index in China $(1992=100)$

Table I. CHNS sample statistics, 1993, 1997, 2000 and 2004

\begin{tabular}{|c|c|c|c|c|}
\hline \multirow[b]{2}{*}{ Variable } & \multicolumn{2}{|c|}{ Male } & \multicolumn{2}{|c|}{ Female } \\
\hline & Mean & Smoking rate & Mean & Smoking rate \\
\hline Ever smoked & 0.591 & & 0.044 & \\
\hline Smoke now & 0.553 & & 0.041 & \\
\hline Cigarettes per day & 16.21 & & 11.21 & \\
\hline Age started & 21.31 & & 28.74 & \\
\hline \multicolumn{5}{|l|}{ Wealth quartiles } \\
\hline Quartile 1 & $25.64 \%$ & 41.26 & $24.46 \%$ & 3.76 \\
\hline Quartile 2 & $25.56 \%$ & 43.23 & $25.82 \%$ & 3.20 \\
\hline Quartile 3 & $25.03 \%$ & 42.95 & $25.18 \%$ & 3.58 \\
\hline Quartile 4 & $23.76 \%$ & 44.13 & $24.54 \%$ & 2.27 \\
\hline \multicolumn{5}{|l|}{ Age } \\
\hline $15-24$ & $16.98 \%$ & 28.76 & $13.79 \%$ & 0.42 \\
\hline $25-44$ & $38.90 \%$ & 64.43 & $39.94 \%$ & 2.14 \\
\hline $45-59$ & $26.67 \%$ & 64.46 & $27.20 \%$ & 5.25 \\
\hline $60+$ & $17.45 \%$ & 46.65 & $19.08 \%$ & 9.14 \\
\hline \multicolumn{5}{|l|}{ Education } \\
\hline None & $6.98 \%$ & 55.29 & $25.16 \%$ & 7.10 \\
\hline Some primary & $19.73 \%$ & 60.12 & $21.19 \%$ & 5.08 \\
\hline Completed primary & $10.31 \%$ & 60.03 & $9.28 \%$ & 5.74 \\
\hline Some lower middle & $39.03 \%$ & 55.78 & $27.77 \%$ & 1.80 \\
\hline Middle/some high school & $14.47 \%$ & 52.86 & $9.96 \%$ & 1.07 \\
\hline High school + & $9.48 \%$ & 44.97 & $6.64 \%$ & 1.45 \\
\hline \multicolumn{5}{|l|}{ Place of residence } \\
\hline City & $13.62 \%$ & 48.96 & $14.49 \%$ & 4.46 \\
\hline Suburb & $18.16 \%$ & 56.08 & $18.15 \%$ & 4.75 \\
\hline Town & $14.91 \%$ & 52.88 & $15.60 \%$ & 2.82 \\
\hline Rural & $53.31 \%$ & 57.32 & $51.76 \%$ & 4.13 \\
\hline
\end{tabular}

In Figure 3 we see that Chinese women follow a much different pattern of life-cycle smoking than men. The $4.6 \%$ of Chinese women who smoke tend to take it up later in life. The female-smoking prevalence rate steadily increases over the life cycle up to its peak of just over $8.0 \%$ around age 53 . Surprisingly, older cohorts of women smoked more at a given age than do younger cohorts.

Figure 4 shifts the frame from a life course to a calendar year perspective to show how smoking rates have changed over time among Chinese men with different levels of schooling. From the 1950s to the 1970s, smoking rates generally increased. From 1975 until the late 1990s, smoking prevalence among the 


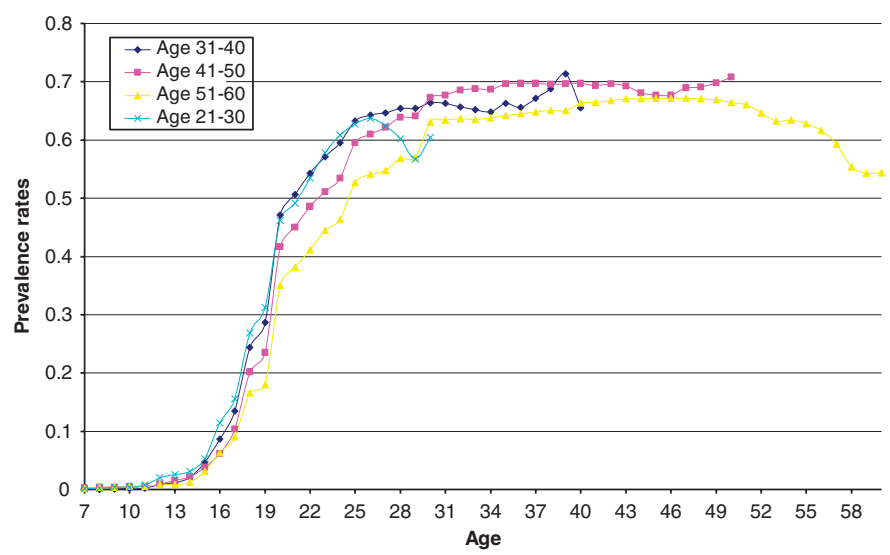

Figure 2. Life-course smoking patterns of Chinese men by age and cohort

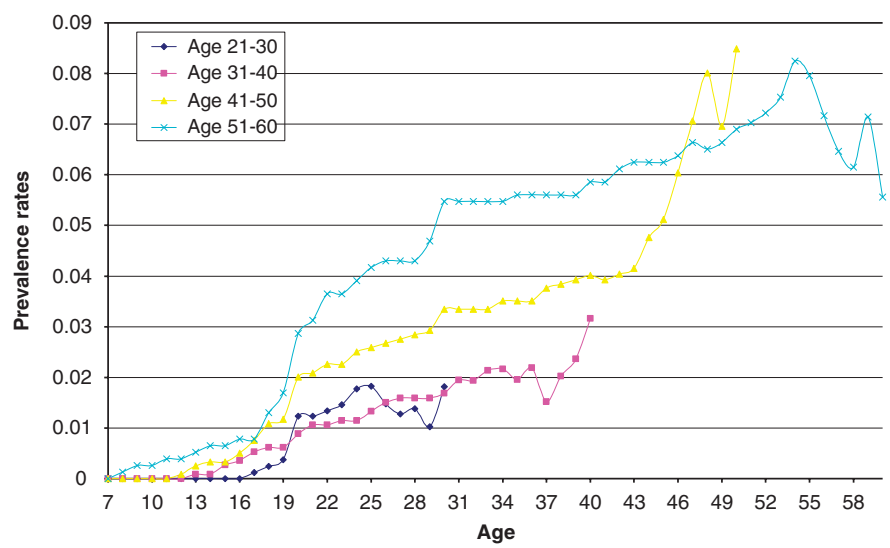

Figure 3. Life-course smoking patterns of Chinese women by age and cohort

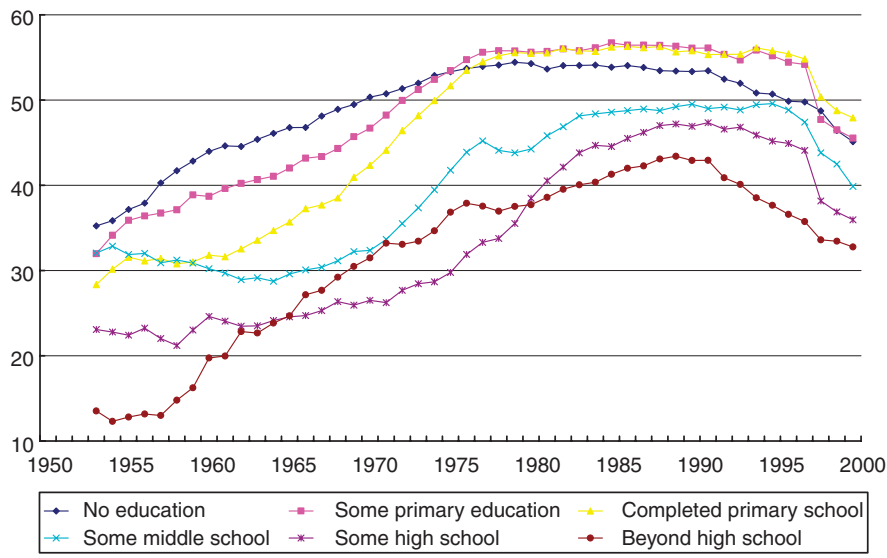

Figure 4. Male smoking prevalence over time by education category

most and least educated group is more or less constant and very different. Smoking participation among men who had completed some middle school or some high school steadily increases until the mid-1990s. Around the mid-1990s smoking rates of all education groups begin to drop. 
As noted before, smoking prevalence rates mix starter and quitters. We next use a standard model of consumer demand to separately analyze the two decisions.

\section{EMPIRICAL APPROACH}

We estimate discrete time hazard models of smoking initiation and cessation of the following general form:

$$
\begin{aligned}
Y= & \beta_{0}+\beta_{1} \text { price }+\beta_{2} \text { education }+\beta_{3} \text { age }+\beta_{4} \text { householdwealth } \\
& +\beta_{5} \text { demographics }+\beta_{6} \text { place of residence }+\beta_{7} \text { survey year }+\varepsilon_{i}
\end{aligned}
$$

where $Y$ equals 1 if a person started or stopped smoking in a particular year and 0 otherwise (conditional on being at risk of starting or stopping). Here price is measured as an index not in log units. A person is in our cessation sample the first year he starts to smoke and he remains in the sample until the year he quits. Because few or no respondents start smoking at older ages, the sample at-risk of smoking initiation excludes person-year observations corresponding to ages over 30 . As a benchmark, we also estimate a smoking participation model where $Y$ equals 1 if a person currently smokes and 0 otherwise. The models include the contemporaneously demographic variables as listed in Table I.

We estimate Equation (1) with retrospectively reported smoking behavior over the years 1952-2000. ${ }^{2}$ Because so few Chinese women smoke, we lack sufficient variation to estimate those models. Therefore, we only estimate the models for Chinese men. We measure the cigarette price as in Figure 1. For simplicity of interpretation, we estimate the models as linear probability models. Broadly similar results from probit models are available on request.

\section{RESULTS}

Table II summarizes the selected results from our models that show the estimated effects of cigarette prices, the time trend and schooling on smoking. We find that the price of cigarettes has small and statistically insignificant effects on smoking participation, initiation and cessation. Because our measure of cigarette prices only varies over time, how we model the time trend has a big impact on the estimated price effects. Our models include linear and quadratic time trends, which we think is a reasonably flexible approach to capture other time-varying influences on smoking, such as the changes in Chinese tobacco control policy described above. If we drop the quadratic terms, the price coefficients become statistically significant and suggest that higher prices reduce smoking participation and initiation, and increase smoking cessation. As we noted above, there is evidence of a possible structural shift in Chinese smoking starting in the early 1970s. There is also more concern about the reliability of retrospective reports in the more distant past. To explore these issues, we tested whether the coefficient on price is different pre- and post-1971 and whether results vary when we replace the time trend with a series of period dummies (i.e. a linear spline). After 1971 the coefficient on price is positive and statistically significant (i.e. it is the 'wrong' sign relative to what theory would predict). Models that use a linear spline with decade long dummies yield price coefficient results consistent with theory. Because the results from the models are not robust to reasonable re-specifications, we are cautious about interpreting our results as very reliable evidence about price effects. More research must explore the basis for the inconsistent results. ${ }^{3}$ We note that Lance et al. (2004) also find the price of cigarettes has a

\footnotetext{
${ }^{2}$ We also Equation (1) with contemporaneously reported data from the 1991, 1993, 1997, 2000 and 2004 surveys using communitylevel prices. Results are available on request.

${ }^{3}$ Because we use retrospectively reported data on smoking, we find evidence that smokers 'heap' reports of time since they last smoked. When we implement the algorithm suggested by Lillard et al. (2009) estimated price effects are consistent with theory.
} 
Table II. Models of smoking participation, initiation and cessation

\begin{tabular}{|c|c|c|c|}
\hline & Participation & Initiation & Cessation \\
\hline Price & $\begin{array}{c}0.018 \\
(0.055)\end{array}$ & $\begin{array}{l}-0.014 \\
(0.014)\end{array}$ & $\begin{array}{l}-0.008 \\
(0.007)\end{array}$ \\
\hline Year & $\begin{array}{c}0.572^{* *} \\
(0.251)\end{array}$ & $\begin{array}{c}0.172^{* * *} \\
(0.059)\end{array}$ & $\begin{array}{c}-0.098^{* * *} \\
(0.032)\end{array}$ \\
\hline Year-squared & $\begin{array}{c}-0.0001^{* *} \\
(0.00006)\end{array}$ & $\begin{array}{c}-0.00004^{* * *} \\
(0.00001)\end{array}$ & $\begin{array}{l}0.00003^{* * *} \\
(0.0000008)\end{array}$ \\
\hline Some primary schooling & $\begin{array}{c}0.019^{* * *} \\
(0.002)\end{array}$ & $\begin{array}{c}0.001 \\
(0.003)\end{array}$ & $\begin{array}{c}0.0008^{* *} \\
(0.0004)\end{array}$ \\
\hline Completed primary school & $\begin{array}{c}0.008^{* *} \\
(0.003)\end{array}$ & $\begin{array}{c}-0.0002 \\
(0.003)\end{array}$ & $\begin{array}{l}0.001^{* *} \\
(0.0006)\end{array}$ \\
\hline Some middle & $\begin{array}{c}-0.009^{* *} \\
(0.005)\end{array}$ & $\begin{array}{l}-0.001 \\
(0.003)\end{array}$ & $\begin{array}{c}0.0008 \\
(0.0005)\end{array}$ \\
\hline Some high school & $\begin{array}{c}-0.055^{* * *} \\
(0.006)\end{array}$ & $\begin{array}{c}-0.009^{* * *} \\
(0.003)\end{array}$ & $\begin{array}{c}0.0002 \\
(0.0006)\end{array}$ \\
\hline High school+ & $\begin{array}{c}-0.118^{* * * *} \\
(0.003)\end{array}$ & $\begin{array}{c}-0.019^{* * * *} \\
(0.003)\end{array}$ & $\begin{array}{c}0.003^{* * *} \\
(0.001)\end{array}$ \\
\hline $\begin{array}{l}\text { Mean of the dependent variable } \\
\text { Sample size (person-vears) }\end{array}$ & 0.457 & 0.052 & 0.003 \\
\hline
\end{tabular}

Notes: Robust standard errors in parentheses. The standard errors for the coefficients on price, year and year-squared are adjusted for year-level clustering. The standard errors for the remaining coefficients are adjusted for individual-level clustering. ${ }^{* * *}$ and ${ }^{* *}$ denote coefficients that statistically differ from zero with $p$-values of $<0.01,<0.05$ and $<0.10$, respectively. Other controls include three age categories, household size, three wealth quartile dummies, 12 occupation dummies, three indicators for suburban, town, or rural residence, eight province dummies and duration of smoking (cessation model only).

very small effect on smoking participation (elasticities under - 0.05). They use the CHNS data but over a shorter time period and with a different price measure.

Table II also lists the estimated coefficients on a series of schooling categories, relative to the omitted category of no formal schooling. Smoking participation tends to fall at higher levels of schooling, particularly among Chinese with a high school education or more. This group is about $12 \%$ points less likely to smoke than the reference category of no schooling. Most of the effect of schooling on smoking participation is through lower smoking initiation. The results from the model of smoking cessation show more complex patterns across schooling categories.

\section{DISCUSSION}

Comparing our results with broad patterns in other countries, we offer some speculative hypotheses that, we hope, might provide guidance for future research on the economics of smoking in China. First, we find that smoking participation among Chinese men increased from 1952 to 2000 . The increase was driven by increases in smoking among the middle education groups. We speculate that this pattern might have occurred because market reforms increased the economic resources of the middle education groups relatively more than it did less well-educated men. The nature of the schooling-smoking gradient also appears to be different in the US than in China. In the US, in groups with the most schooling, smoking participation rates sharply fell over this same time period (Kenkel and Liu, 2008). In China, among men with a high school education or more, smoking participation has ranged between $30 \%$ and $45 \%$ for several decades. We speculate that more schooling may have had a protective effect, so that their economic gains from the market reforms at least did not increase their smoking rates.

Second, we find that the rate of smoking cessation among Chinese smokers is very low. A useful summary statistic is the ratio of former smokers to ever smokers. In the US, this ratio has risen to about 0.5 , meaning that half of all ever smokers alive today have quit smoking. By contrast, among Chinese men the ratio of former smokers to ever smokers is only about 0.06 . Almost all of Chinese ever smokers remain current smokers. Because smoking cessation rates are so low, our econometric model has low statistical 
power to detect influences that might help increase smoking cessation. However, we speculate that increases in schooling and economic resources may be setting the stage for substantial increases in smoking cessation in China. It has often been noted that the Chinese market for cigarettes is an attractive target for the tobacco industry. We point out that the Chinese market for smoking cessation products is an equally attractive target for the pharmaceutical industry to earn private profits while promoting public health (Avery et al., 2007).

As a final comment, we note that much more research is needed on the effectiveness of tobacco control policies in China. While our life course approach provides new insights about broad patterns in smoking, data limitations mean that we were unable to shed much light on the effectiveness of higher prices and other elements of tobacco control policies. In part our analysis was limited by the paucity of time series cigarette price data that for different regions in China. Were such data available, it would be possible to estimate much more robust and richer models of initiation and cessation with the CHNS life-course data. Further, anecdotal evidence suggests that policies adopted around the Beijing Olympics might have been a watershed in Chinese tobacco control. These changes might provide a useful 'natural experiment' to study the impact of tobacco control policies in China.

\section{ACKNOWLEDGEMENTS}

Liu gratefully acknowledges the support of the 'Leading Academic Discipline Program, 211 Project for Shanghai University of Finance and Economics.' Kenkel and Liu gratefully acknowledge support from Cornell University through the Jeffrey S. Lehman Fund for Scholarly Exchange with China.

\section{CONFLICT OF INTEREST}

The authors have no conflicts of interest to declare.

\section{APPENDIX: FULL MODEL RESULTS}

\begin{tabular}{lccc}
\hline & Participation & Initiation & Cessation \\
\hline Price & 0.018 & -0.014 & -0.008 \\
& $(0.055)$ & $(0.014)$ & $(0.007)$ \\
Year & $0.572^{* *}$ & $0.172^{* * *}$ & $-0.098^{* * *}$ \\
& $(0.251)$ & $(0.059)$ & $(0.032)$ \\
Year-squared & $-0.0001^{* *}$ & $-0.00004^{* * *}$ & $0.00003^{* * *}$ \\
& $(0.00006)$ & $(0.00001)$ & $(0.0000008)$ \\
Some primary schooling & $0.019^{* * *}$ & 0.001 & $0.0008^{* *}$ \\
& $(0.002)$ & $(0.003)$ & $(0.0004)$ \\
Completed primary school & $0.008^{* *}$ & -0.0002 & $0.001^{* *}$ \\
& $(0.003)$ & $(0.003)$ & $(0.0006)$ \\
Some middle & $-0.009^{* *}$ & -0.001 & 0.0008 \\
& $(0.005)$ & $(0.003)$ & $(0.0005)$ \\
Some high school & $-0.055^{* * *}$ & $-0.009^{* * *}$ & 0.0002 \\
& $(0.006)$ & $(0.003)$ & $(0.0006)$ \\
High school + & $-0.118^{* * *}$ & $-0.019^{* * *}$ & $(0.003)$ \\
& $(0.003)$ & & $0.003^{* * *}$ \\
& & $0.001)$ \\
\hline
\end{tabular}




\begin{tabular}{|c|c|c|c|}
\hline Age $25-44$ & $\begin{array}{c}0.290^{* * *} \\
(0.004)\end{array}$ & $\begin{array}{c}-0.017^{* * *} \\
(0.002)\end{array}$ & $\begin{array}{c}-0.00006 \\
(0.0004)\end{array}$ \\
\hline Age $45-59$ & $0.277^{* * * *}$ & & $0.002^{* *}$ \\
\hline Age $60+$ & $\begin{array}{c}0.164^{* * *} \\
(0.010)\end{array}$ & & $\begin{array}{c}0.011^{* * *} \\
(0.002)\end{array}$ \\
\hline Wealth quartiles 2 & $\begin{array}{c}0.005^{* *} \\
(0.002)\end{array}$ & $\begin{array}{c}0.002 \\
(0.002)\end{array}$ & $\begin{array}{l}0.0005^{*} \\
(0.0003)\end{array}$ \\
\hline Wealth quartiles 3 & $\begin{array}{c}0.013^{* * *} \\
(0.003)\end{array}$ & $\begin{array}{c}0.006^{* * *} \\
(0.002)\end{array}$ & $\begin{array}{c}0.0007 \\
(0.0004)\end{array}$ \\
\hline Wealth quartiles 4 & $\begin{array}{c}0.020^{* * * *} \\
(0.005)\end{array}$ & $\begin{array}{c}0.009^{* * *} \\
(0.002)\end{array}$ & $\begin{array}{c}0.0012^{* * *} \\
(0.0005)\end{array}$ \\
\hline Occupation 2 & $\begin{array}{l}-0.002 \\
(0.006)\end{array}$ & $\begin{array}{c}0.001 \\
(0.005)\end{array}$ & $\begin{array}{r}-0.003^{*} \\
(0.002)\end{array}$ \\
\hline Occupation 3 & $\begin{array}{c}0.052^{* * *} \\
(0.005)\end{array}$ & $\begin{array}{l}0.008^{*} \\
(0.004)\end{array}$ & $\begin{array}{c}-0.004^{* * *} \\
(0.001)\end{array}$ \\
\hline Occupation 4 & $\begin{array}{c}-0.011^{*} \\
(0.005)\end{array}$ & $\begin{array}{c}0.002 \\
(0.004)\end{array}$ & $\begin{array}{l}-0.002 \\
(0.002)\end{array}$ \\
\hline Occupation 5 & $\begin{array}{c}0.062^{* * *} \\
(0.005)\end{array}$ & $\begin{array}{c}0.017^{* * *} \\
(0.004)\end{array}$ & $\begin{array}{c}-0.003^{* *} \\
(0.001)\end{array}$ \\
\hline Occupation 6 & $\begin{array}{l}-0.002 \\
(0.005)\end{array}$ & $\begin{array}{c}0.004 \\
(0.004)\end{array}$ & $\begin{array}{c}-0.003^{* *} \\
(0.001)\end{array}$ \\
\hline Occupation 7 & $\begin{array}{l}-0.003 \\
(0.004)\end{array}$ & $\begin{array}{c}0.003 \\
(0.004)\end{array}$ & $\begin{array}{c}-0.003^{* *} \\
(0.001)\end{array}$ \\
\hline Occupation 8 & $\begin{array}{c}-0.020^{* * *} \\
(0.006)\end{array}$ & $\begin{array}{l}-0.008 \\
(0.009)\end{array}$ & $\begin{array}{l}-0.004 \\
(0.003)\end{array}$ \\
\hline Occupation 9 & $\begin{array}{c}-0.023^{* *} \\
(0.009)\end{array}$ & $\begin{array}{c}0.002 \\
(0.009)\end{array}$ & $\begin{array}{l}-0.005 \\
(0.003)\end{array}$ \\
\hline Occupation 10 & $\begin{array}{c}0.005 \\
(0.006)\end{array}$ & $\begin{array}{c}0.006 \\
(0.005)\end{array}$ & $\begin{array}{c}-0.005^{* * *} \\
(0.002)\end{array}$ \\
\hline Occupation 11 & $\begin{array}{c}0.020^{* * *} \\
(0.003)\end{array}$ & $\begin{array}{c}0.003 \\
(0.004)\end{array}$ & $\begin{array}{c}-0.004^{* *} \\
(0.002)\end{array}$ \\
\hline Occupation 12 & $\begin{array}{c}0.163^{* * *} \\
(0.012)\end{array}$ & $\begin{array}{c}0.027 \\
(0.021)\end{array}$ & $\begin{array}{c}-0.005^{* * *} \\
(0.001)\end{array}$ \\
\hline Occupation 13 & $\begin{array}{c}-0.039^{* * *} \\
(0.003)\end{array}$ & $\begin{array}{l}-0.001 \\
(0.003)\end{array}$ & $\begin{array}{l}-0.002 \\
(0.001)\end{array}$ \\
\hline Suburb & $\begin{array}{c}-0.015^{* * *} \\
(0.003)\end{array}$ & $\begin{array}{l}-0.002 \\
(0.003)\end{array}$ & $\begin{array}{c}-0.001^{*} \\
(0.0005)\end{array}$ \\
\hline Town & $\begin{array}{c}-0.016^{* * *} \\
(0.003)\end{array}$ & $\begin{array}{l}-0.002 \\
(0.003)\end{array}$ & $\begin{array}{l}-0.0006 \\
(0.0007)\end{array}$ \\
\hline Rural & $\begin{array}{c}-0.035^{* * *} \\
(0.002)\end{array}$ & $\begin{array}{c}-0.009^{* * *} \\
(0.002)\end{array}$ & $\begin{array}{c}-0.001^{* *} \\
(0.0005)\end{array}$ \\
\hline Heilongjiang province & $\begin{array}{c}-0.011^{* * *} \\
(0.003)\end{array}$ & $\begin{array}{l}-0.003 \\
(0.003)\end{array}$ & $\begin{array}{l}-0.001 \\
(0.001)\end{array}$ \\
\hline
\end{tabular}




\begin{tabular}{lccc}
\hline Jiangsu province & -0.002 & $-0.006^{*}$ & $0.002^{* * *}$ \\
& $(0.004)$ & $(0.003)$ & $(0.0006)$ \\
Shandong province & $-0.017^{* * *}$ & -0.006 & $0.002^{* *}$ \\
& $(0.006)$ & $(0.003)$ & $(0.0009)$ \\
Henan province & $-0.029^{* * *}$ & $-0.008^{* * *}$ & $0.002^{* *}$ \\
Hubei province & $(0.004)$ & $(0.003)$ & $(0.0007)$ \\
& -0.002 & -0.005 & $0.001^{* * *}$ \\
Hunan province & $(0.003)$ & $(0.003)$ & $(0.0005)$ \\
Guangxi province & $0.048^{* * *}$ & 0.002 & 0.0002 \\
& $(0.006)$ & $(0.004)$ & $(0.0006)$ \\
Guizhou province & $-0.014^{*}$ & $-0.011^{* * *}$ & 0.0003 \\
& $(0.007)$ & $(0.003)$ & $(0.0005)$ \\
Number of household members & $0.067^{* * *}$ & $0.014^{* * *}$ & -0.0004 \\
& $(0.004)$ & $(0.003)$ & $(0.0005)$ \\
Number of years smoked & $-0.004^{* * *}$ & $-0.001^{*}$ & $-0.0002^{*}$ \\
& $(0.0003)$ & $(0.0005)$ & $(0.0001)$ \\
Constant & & & $0.00005^{*}$ \\
& & & $(0.00003)$ \\
Mean of the dependent variable & $-567.3^{* *}$ & $-170.3^{* * *}$ & $96.88^{* * *}$ \\
Sample size (person-years) & $(247.4)$ & $(57.80)$ & $(31.88)$ \\
\hline
\end{tabular}

$* * *, * *$ and ${ }^{*}$ denote coefficients that statistically differ from zero with $p$-values of $<0.01,<0.05$ and $<0.10$ respectively. Default categories: no education, occupation of senior professional/technical, living in city and in Liaoning province. Occupation categories:

01 Senior professional/technical worker (doctor, professor, lawyer, architect and an engineer)

02 junior professional/technical worker (midwife, nurse, teacher, an editor and photographer)

03 Administrator/executive/manager (working proprietor, government official, section chief, department or bureau director, administrative cadre and village leader)

04 Office staff (secretary and office helper)

05 Farmer, fisherman and hunter

06 Skilled worker (foreman, group leader and craftsman)

07 Non-skilled worker (ordinary laborer and logger)

08 Army officer and police officer

09 Ordinary soldier and policeman

10 Driver

11 Service worker (housekeeper, cook, waiter, doorkeeper, hairdresser, counter salesperson, launderer and child care worker)

12 Athlete, actor and musician

13 Other.

\section{REFERENCES}

Avery R, Kenkel D, Lillard DR, Mathios A. 2007. Private profits and public health: does DTC advertising of smoking cessation products encourage smokers to quit? Journal of Political Economy 115(3): 447-481 (also NBER working paper 11938).

Bishop J, Liu H, Meng Q. 2007. Are Chinese smokers sensitive to price? China Economic Review 18(2): 113-121.

DeCicca P, Kenkel DS, Mathios AD. 2008. Cigarette taxes and the transition from youth to adult smoking: smoking initiation, cessation, and participation. NBER Working Papers 14042, National Bureau of Economic Research, Inc.

Hu T-W, Mao Z. 2002. The effects of cigarette tax on cigarette consumption and the Chinese economy. Tobacco Control 11(10): 5-108.

Kenkel D, Lillard DR, Mathios A. 2003a. Smoke or fire? are retrospective smoking data valid? Addiction 98(9): $1307-1313$. 
Kenkel D, Lillard DR, Mathios A. 2003b. Tobacco control policies and smoking cessation: a cross-country analysis Schmollers Jahrbuch. Journal of Applied Social Science Studies 123(1): 221-234.

Kenkel D, Liu F. 2008. The Evolution of the Schooling-smoking Gradient. Manuscript. Department of Policy Analysis and Management, Cornell University, NY, USA.

Lam TH, He Y, Li LS, He SF, Liang BQ. 1997. Mortality attributable to cigarette smoking in China. Journal of the American Medical Association 278(18)(November): 1505-1508.

Lance PM, Akin JS, Dow WH, Loh C. 2004. Is cigarette smoking in poorer nations highly sensitive to price? Evidence from Russia and China. Journal of Health Economics 23: 173-189.

Lillard DR, Bar HY, Wang H. 2009. A heap of trouble? Accounting for mismatch bias in retrospectively reported data (with application to smoking cessation and (non) employment). Manuscript. Department of Policy Analysis and Management, Cornell University.

Liu BQ, Peto R, Chen ZM, Boreham J, Wu YP, Li JY, Campbell TC, Chen JS. 1998. Emerging tobacco hazards in China: 1. Retrospective proportional mortality study of one million deaths. British Medical Journal 317(7170): $1411-1422$.

Mao ZZ, Jiang JL. 1997. Determinants of the demand for cigarettes, a cross-sectional study. Chinese Health Industry Management 227-229.

Mao ZZ, Jiang JL, Gong ZP. 1997. Demand for cigarette and pricing policy: a time-series analysis. Chinese Health Economics 16(172): 50-52.

World Health Organization. 2008. WHO report on the global tobacco epidemic, 2008 - The MPOWER package. Available at: http://www.who.int/tobacco/mpower/gtcr_download/en/index.html. 